\title{
Safety and Efficacy of Fixed Dose Combination of Glimepiride and Metformin in Type 2 Diabetic Patients in Egypt: A Real-Life Study
}

\author{
MOHAMED F. ABD AL-AZIZ, M.D.*; MANAL ABU SHADY, M.D.** and \\ SAMIR ABD EL-HAMID, M.D.*** \\ The Departments of Internal Medicine Units of Endocrine*, Diabetes \& Endocrinology** and Gastroenterology***, \\ Faculty of Medicine, Ain Shams University, Egypt
}

\begin{abstract}
Background: Previous reports showed a significant improvement in the glycemic control of patients with Type 2 Diabetes Mellitus (T2DM) following the use of Glimepiride/ Metformin Fixed-Dose Combination (G/M FDC), with a reasonable safety profile. In this real-life study on Egyptian population, we aim to investigate the safety and effectiveness of G/M FDC among patients with T2DM.
\end{abstract}

Subjects and Methods: The present observational, multicenter study included 1211 T2DM patients from Egypt, for whom the investigator decided to prescribe G/M FDC. Patients started G/M FDC at the beginning of the study or one month earlier, and the combination dose was decided by the investigators to reflect the in-practice approach. Data were recorded at the initial assessment visit and six months later. Safety outcomes were measured throughout the course of treatment.

Results: At the end of six months follow-up duration, $45.2 \%$ of the patients achieved the targeted $\mathrm{HbA} 1 \mathrm{c} \leq 7 \%$ and $79.5 \%$ achieved the targeted reduction in $\mathrm{HbA} 1 \mathrm{c}$ by $\geq 0.7 \%$. The total percentage of patients who achieved either the targeted $\mathrm{HbA} 1 \mathrm{c} \leq 7 \%$ or reduction in $\mathrm{HbA} 1 \mathrm{c} \geq 0.7 \%$ were $86.5 \%$, while those who achieved both target $\mathrm{HbA} 1 \mathrm{c} \leq 7 \%$ and reduction in $\mathrm{HbA} 1 \mathrm{c} \geq 0.7 \%$ constituted $38.3 \%$ of the patients. The mean $\mathrm{HbA} 1 \mathrm{c}$ level reduced throughout the study period from $8.8 \pm 1.3 \%$ to $7.3 \pm 0.9 \%$ at the end sixth month $(p<0.001)$. Hyperglycemia was the most commonly reported adverse events $(3.5 \%)$, followed by hypoglycemia (1.2\%).

Conclusion: The prescription of G/M FDC in treating patients with T2DM in Egypt is effective in achieving the targeted glycemic control with tolerable safety profile.

Key Words: Glimepiride/Metformin - HbAlc - Hypoglycaemia $-T 2 D M$.

\section{Introduction}

THE increasing prevalence of Type 2 Diabetes Mellitus (T2DM) is a public health concern. Although T2DM may result in a wide range of micro-

Correspondence to: Dr. Mohamed F. Abd Al-Aziz, The Department of Internal Medicine Unit of Endocrine, Faculty of Medicine, Ain Shams University, Egypt and macrovascular complications, the early management of the disease from the time of diagnosis can minimize these consequences [1,2]. Oral Antidiabetics (OADs) lower the blood glucose level through a number of proposed mechanisms including stimulation of insulin secretion, reducing insulin resistance, and increasing glucagon-like-peptide1 secretion [3].

However, recent reports reveal growing evidence that regimens adopting monotherapy of OADs failed to control the glycemic status of T2DM patients, and the need for maximal dose with monotherapy may increase the risk of serious complications. In order to reduce the need for dose titration, it is recommended to use a combination regimen with a complementary mechanism. Of these combinations, Glimepiride/Metformin Fixeddose Combination (G/M FDC) has shown a promising effect on insulin secretion and significant improvement in insulin resistance [4-6]

In addition, the current literature shows that FDCs of OADs can improve patient compliance compared with instructing the patient to multiple pills. It is also suggested that these combinations may minimize the side effects resulting from prescribing high-dose monotherapy to T2DM patients [7]. As a result of high patients' compliance and the reported cost-effectiveness, the use G/M FDC has been recently increased worldwide [8]

Despite the worldwide consensus recommendations, data is lacking about the real-life practice of G/M FDC in treating patients with T2DM in Egypt. In this regards, the present study aimed to evaluate the efficacy and safety of G/M FDC among Egyptian patients with T2DM. 


\section{Subjects and Methods}

In the present observational, multi-center, prospective study, we randomly selected physicians from multiple private centers in Egypt from July 2014 till March 2016. Each participating physician was asked to include consecutive patients during the recruitment period starting from the initiation date at each site. Patients, with poorly controlled T2DM on OADs, were included if they met the following criteria: (1) Patient age $\geq 21$ years old, (2) Patient who received G/M FDC initiated at the baseline visit or one month earlier and (3) Patients who agreed to sing the informed consent form. Patients were excluded if they had severe hepatic/ renal disorders, reported hypersensitivity to sulfonylureas or metformin, or contraindications to $\mathrm{G} / \mathrm{M}$ FDC.

The following data were recorded for every patient: Demographic characteristics, medical history, and HbA1c levels. The data were collected at the initial assessment visit and six months later. Safety outcomes were measured throughout the course of treatment. All adverse events, whether related to G/M FDC or not, were recorded from the first day of administration. The severity of the adverse events and corrective medications were also monitored.

The dosing regimens and the need to add insulin or other medications were left to the investigators in order to experience the real-life practice.

The primary endpoints included the following: The percentage of patients who achieved $\mathrm{HbA} 1 \mathrm{c}$ $\leq 7.0 \%$ or a decrease in $\mathrm{HbA} 1 \mathrm{c} \geq 0.7 \%$ after six months of treatment, the percentage of patients who needed to switch to insulin, and the percentage of patients who experienced adverse events which necessitate a change or discontinuation of treatment. The secondary outcomes were the mean change in HbA1c and Fasting Blood Glucose (FBG) levels at the end of study weight change from baseline, treatment adherence, and safety outcomes.

Data entry, verification, and validation were carried out using standard computer software. A double-entry method was used to ensure that the data were transferred accurately from the case report forms to the database. Data were analyzed using the software, Statistical Package for Social Science (SPSS Inc. Released 2009, PASW Statistics for Windows, Version 18.0: SPSS Inc., Chicago, Illinois, USA), then processed and tabulated. Frequency distribution with its percentage and descriptive statistics with mean and standard deviation were calculated. Chi-square, $t$-test, correlations were done whenever needed. $p$-values of less than 0.05 were considered significant.

The study was conducted in full accordance with the guidelines for Good Clinical Practice and the Declaration of Helsinki, and data for each patient were collected only after obtaining that patient's signed written data release forms.

\section{Results}

A total of 1211 patients from Egypt with T2DM, for whom the investigator decided to prescribe G/M FDC, were screened for eligibility. From which 31 patients did not meet the eligibility criteria (30 patients were not prescribed G/M FDC at baseline, and one patient had missing data for baseline Insulin). Thus the overall number of eligible patients enrolled in the descriptive analysis stood was 1180 patients. At the end of follow-up, the primary study endpoint was not recorded for 80 subjects (20 subjects were lost to follow-up and 60 subjects did not undergo HbA1c level measurements at six months). So, the efficacy population included only 1100 patients.

The mean age of the included patients was $50.4 \pm 9.6$ years with a BMI of $30.8 \pm 5 \mathrm{~kg} / \mathrm{m}^{2}$. Slightly more than half $(52.7 \%)$ of the patients were males. Most of the patients (74.2\%) were residing urban areas, and the remaining patients were living in rural $(18.7 \%)$ or suburban $(7 \%)$ areas. The mean duration of disease was $4.8 \pm 5.2$ years. Two-thirds of patients reported a positive family history of diabetes, $42.4 \%$ had complications associated with T2DM; these complications were mainly nervous system disorders $(36.3 \%)$, cardiac disorders $(10.7 \%)$, and eye disorders $(8.8 \%)$, while $55.5 \%$ had medical or surgical complications rather than diabetes. Regarding previous anti-diabetic therapies prior to baseline visit, metformin were used by $39.5 \%$ of the patients, sulfonylureas were used by $36.4 \%$ of the patients, and $22.8 \%$ of the patients were instructed to G/M FDC. Only $5.3 \%$ of patients were prescribed to insulin prior to enrollment into the study. All patients were shifted to the G/M FDC before the enrollment in this study (Table 1).

The included patients were prescribed one of the following four dosing regimens: (1) A single oral administration of fixed dose $2 \mathrm{mg}$ Glimepiride plus 500mg Metformin (1 X 2/500mg G/M FDC) received by $92.6 \%$ of the participants, (2) $4 \mathrm{mg}$ Glimepiride plus $1000 \mathrm{mg}$ Metformin daily ( $2 \mathrm{X}$ $2 / 500 \mathrm{mg} \mathrm{G} / \mathrm{M}$ ) received by $6.6 \%$ of the participants, (3) Fixed dose combination of $1 \mathrm{mg}$ Glimepiride plus $250-\mathrm{mg}$ Metformin ( 1 X 1/250mg G/M) received by $0.5 \%$ of the participants, or (4) $3 \mathrm{mg}$ 
Glimepiride plus 750mg Metformin (1 X 2/500mg and $1 \times 1 / 250 \mathrm{mg} \mathrm{G} / \mathrm{M}$ ) received by $0.3 \%$ of the participants.

Table (1): Baseline characteristics of the included patients.

\begin{tabular}{|c|c|}
\hline Characteristics & $\begin{array}{l}\text { Frequency, }(\%) \\
(\text { Total }=1180)\end{array}$ \\
\hline - Age (mean $\pm \mathrm{SD})$ years & $50.4 \pm 9.6$ \\
\hline $\begin{array}{l}\text { - Sex: } \\
\text { Male } \\
\text { Female }\end{array}$ & $\begin{array}{l}622(52.7) \\
558(47.3)\end{array}$ \\
\hline - BMI (mean $\pm \mathrm{SD}) \mathrm{kg} / \mathrm{m}^{2}$ & $30.8 \pm 5.0$ \\
\hline $\begin{array}{l}\text { - Residence: } \\
\text { Rural } \\
\text { Urban } \\
\text { Suburban }\end{array}$ & $\begin{array}{l}221(18.7) \\
876(74.2) \\
83(7.0)\end{array}$ \\
\hline $\begin{array}{l}\text { - Educational level: } \\
\text { Illiterate } \\
\text { Elementary Education } \\
\text { Higher Education }\end{array}$ & $\begin{array}{l}145(12.3) \\
454(38.5) \\
581(49.2)\end{array}$ \\
\hline - Duration (mean $\pm \mathrm{SD})$ years & $4.8 \pm 5.2$ \\
\hline - Baseline HbA1 c (mean \pm SD) level & $8.8 \pm 1.3$ \\
\hline - Baseline FBG (mean $\pm \mathrm{SD}$ ) level, mg/dL & $203.7 \pm 62.6$ \\
\hline - Baseline weight (mean \pm SD) $\mathrm{Kg}$ & $87.9 \pm 13.7$ \\
\hline - Positive family history & $786(66.6)$ \\
\hline - Diabetes-related complications & $500(42.4)$ \\
\hline - Medical or surgical history & $655(55.5)$ \\
\hline $\begin{array}{l}\text { - Prescribed to Insulin before the initial assessment } \\
\text { level. }\end{array}$ & $62(5.3)$ \\
\hline $\begin{array}{l}\text { - Prescribed to Glimepiride/Metformin before the } \\
\text { initial assessment level. }\end{array}$ & $269(22.8)$ \\
\hline Smoking habits: & \\
\hline $\begin{array}{l}\text { Never } \\
\text { Current } \\
\text { Former }\end{array}$ & $\begin{array}{l}753(63.8) \\
245(20.8) \\
182(15.4)\end{array}$ \\
\hline
\end{tabular}

Regarding the primary endpoints, a total of 497 $(45.2 \%)$ patients achieved the targeted $\mathrm{HbAlc}$ $\leq 7 \%$, and 875 patients $(79.5 \%)$ achieved the targeted reduction in $\mathrm{HbA} 1 \mathrm{c}$ level by $\geq 0.7 \%$. The total number of responders who achieved either target $\mathrm{HbA} 1 \mathrm{c} \leq 7 \%$ or reduction in $\mathrm{HbA} 1 \mathrm{c}$ by $\geq 0.7 \%$ were $951(86.5 \%)$, while, those who achieved both target $\mathrm{HbA} 1 \mathrm{c} \leq 7 \%$ and reduction in $\mathrm{HbA} 1 \mathrm{c}$ by $\geq 0.7 \%$ were $421(38.3 \%)$ Fig. (1). Only $8.1 \%$ of the patients needed an add-on insulin therapy for the following reasons: $75(6.8 \%)$ patients did not achieve target HbA1c levels, 61 (5.5\%) patients did not achieve target FPG level, 37 (3.4\%) patients experienced hyperglycemia, $6(0.5 \%)$ patients had weight gain, $5(0.5 \%)$ patients showed new T2DMrelated complications, and $2(0.2 \%)$ patients reported worsening of pre-existing T2DM-related complications. Throughout the study period, no patients experienced adverse events which necessitate a change or discontinuation of treatment.

The mean $\mathrm{HbA} 1 \mathrm{c}$ level reduced throughout the study period from $8.8 \pm 1.3 \%$ to $7.3 \pm 0.9 \%$ at the end of sixth month $(p<0.001)$. While, the FBG level decreased significantly from $203.7 \pm 62.6 \mathrm{mg} / \mathrm{dl}$ to $131.8 \pm 33.2 \mathrm{mg} / \mathrm{dl}$ following six months of treatment $(p<0.001)$. Similar significant reduction was observed in the mean weight at the end of study period $(87.9 \pm 13.7$ to $86 \pm 12.6 \mathrm{~kg} ; p<0.001)$. The total number of adverse event stood at 70 events distributed on 57 (4.7\%) patients. Sixteen patients $(1.6 \%)$ did not receive glimepiride/metformin as initially prescribed. Reasons for this lack of compliance included incidence of hyperglycemia in 11 patients $(1 \%)$, hypoglycemia in 4 patients $(0.4 \%)$ and poor patient adherence to the combination therapy in 1 patient $(0.1 \%)$.

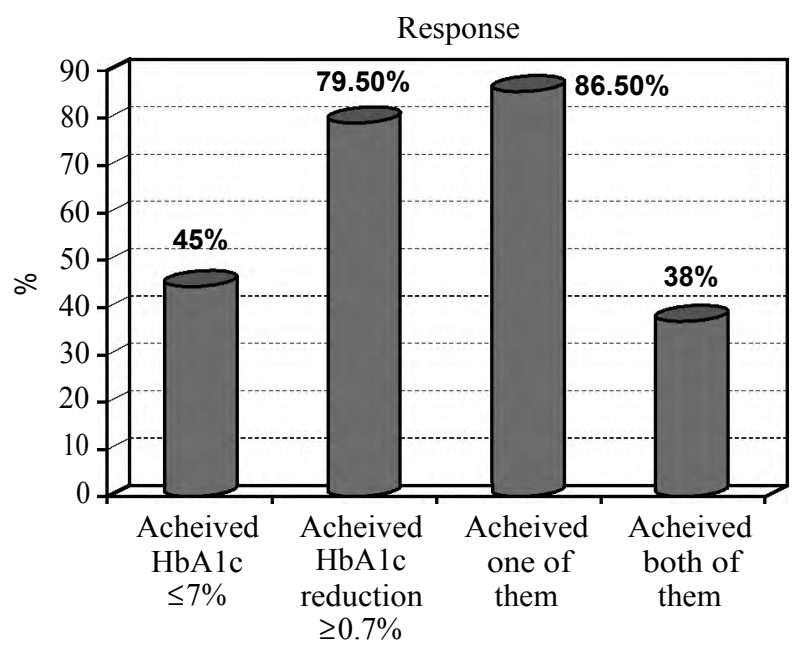

Fig. (1): Response of the participating patients to treatment after 6 months.

Throughout the study period, 57 patients $(4.7 \%)$ experienced 70 adverse events. The most commonly reported adverse events were $15(1.2 \%)$ hypoglycemic events, 43 (2.8\%) hyperglycemic events, and $6(0.5)$ weight gain events. The incidences of acute adverse events among the participants are shown in (Table 2).

Table (2): Incidence of acute adverse events among the included patients.

\begin{tabular}{|c|c|}
\hline Adverse events & $\begin{array}{c}\text { Frequency, }(\%) \\
(\text { Total }=1180)\end{array}$ \\
\hline Hypoglycemia & $15(1.2)$ \\
\hline Hyperglycemia & $43(2.8)$ \\
\hline Foot Ulcer & $3 \quad(0.3)$ \\
\hline Microalbuminurea & $1 \quad(0.1)$ \\
\hline Neuropathy & $2 \quad(0.2)$ \\
\hline Weight Gain & $6 \quad(0.5)$ \\
\hline
\end{tabular}

*Every subject may had more than one AEs/ADRs.

\section{Discussion}

Glimepiride and metformin are one of the most commonly prescribed OADs worldwide. Metformin is reported to improve the peripheral resistance to 
insulin and is widely recommended as the first choice OAD for newly diagnosed T2DM patients. While glimepiride is a third generation sulfonylurea that enhances insulin secretion. Compared to conventional sulfonylureas, glimepiride was reported to have a higher selectivity toward the pancreatic ATP-sensitive potassium channel and greater improvement in glucose transport. Meanwhile, glimepiride has been prescribed as a primary OAD, especially when metformin monotherapy has no effect. The combination regimen of metformin and glimepiride showed clinically significant more improvement in glycemic status when compared to either metformin or glimepiride monotherapy. G/M FDC was reported to control the hyperglycemic status of T2DM patients and reduce the side effects resulting from the need for the maximal dose of monotherapy [5-7].

In the present prospective real-life study, $45.2 \%$ of included T2DM patients achieved the target $\mathrm{HbA} 1 \mathrm{c} \leq 7 \%$, while $79.5 \%$ showed more than $0.7 \%$ reduction in $\mathrm{HbA} 1 \mathrm{c}$ levels at the end of followup. Up to $86.5 \%$ achieved at least one of both targets. The mean change in $\mathrm{HbA} 1 \mathrm{c}$ levels was -1.5 at the end of the six months duration ( $p$ $<0.001)$. G/M FDC exhibits a tolerable safety profile as well, only 70 adverse events were reported, mostly hyperglycemia and hypoglycemia.

In consistent with our findings, a study on 209 Korean T2DM patients showed that G/M FDC provided better glycemic control and lower side effects compared to monotherapy [9]. In a previously published study over the use of G/M FDC in a single dose for a 3-month follow-up study, a reduction of $1.3 \%$ in the levels of $\mathrm{HbA} 1 \mathrm{c}$ was reported and nearly half of the patients showed targeted $\mathrm{HbA} 1 \mathrm{c}$ reduction [10]. G/M FDC demonstrated a higher efficacy than metformin combination with older sulfonylureas in previously published controlled trials, as well. In one randomized controlled trial, a higher proportion of the patients G/M FDC group reached $\mathrm{HbA} 1 \mathrm{c}$ level $\leqslant 7 \%$ at the end of 12 months follow-up compared to glibenclamide/metformin, the observed difference was statistically significant [11].

Generally, sulfonylureas are expected to be associated with more risk of hypoglycemia than other classes of medication due to its insulin secretagogue effect. However, recent reports suggested that glimepiride lead to lower rate of severe hypoglycemia than other sulfonylureas, which may be attributed to its potentially controllable effect on insulin secretion [12]. In the present study, only $1.2 \%$ of included patients developed hypoglycemic events. González-Ortiz et al., conducted a randomized controlled trial in 152 poorly controlled T2DM and reported an incidence rate of $17.1 \%$ of hypoglycemic events among G/M FDC group [11], which was much higher than our observed results. However, no sever hypoglycemic events were reported in any of the abovementioned studies.

It has been previously reported that dose titration of FDCs are difficult to achieve, therefore, may lead to hyperglycemia in patients who required dose titrations [7]. In the present study, the majority of the patients (92\%) received G/M FDC at dose of $2 / 500 \mathrm{mg}$ and we observed 43 incidence of acute hyperglycemic episodes. However, it should be noted that FDCs are available in a variety of doses which may allow the clinician to choose the optima titration and dose adjustments strategy [13].

In conclusion, the prescription of G/M FDC in treating patients with T2DM in Egypt is an effective strategy that exhibit a significant improvement in glycemic control with tolerable safety profile. Our study was a real-life one which have the advantages of simulating "real" patients.

\section{Acknowledgment:}

The study was sponsored and funded by Sanofi, which played no role in analyzing or interpreting the data. A statistical analysis was provided by RAY Contract Research Organization. Editorial support was provided by Ahmed Elgebaly, Reham Elgarhy and Fady Adel of RAY Contract Research Organization and was funded by Sanofi.

\section{Authors' COI:}

The author has no conflicts of interest to declare.

\section{References}

1- TURNER R.: Effect of intensive blood-glucose control with metformin on complications in overweight patients with type 2 diabetes (UKPDS 34). Lancet, 352 (9131): 854-65. Doi: 10.1016/S0140-6736(98)07037-8, 1998.

2- HOLMAN R.R., PAUL S.K., BETHEL M.A., MATTHEWS D.R. and NEIL H.A.W.: 10-year follow-up of intensive glucose control in type 2 diabetes. N. Engl. J. Med., 359 (15): 1577-1589. doi: 10.1056/NEJMoa0806470, 2008.

3- TURNER R.C., CULL C.A., FRIGHI V. and HOLMAN R.R.: Glycemic control with diet, sulfonylurea, metformin, or insulin in patients with type 2 diabetes mellitus: Progressive requirement for multiple therapies (UKPDS 49). UK Prospective Diabetes Study (UKPDS) Group. JAMA, 281 (21): 2005-12. doi: 10.1017/CBO9781107415324.004, 1999.

4- MELIKIAN C., WHITE T.J., VANDERPLAS A., DEZII C.M. and CHANG E.: Adherence to oral antidiabetic therapy in a managed care organization: A comparison of monotherapy, combination therapy, and fixed-dose com- 
bination therapy. Clin. Ther., 24 (3): 460-7. Doi: 10.1016/ S0149-2918(02)85047-0, 2002.

5- GEISEN K., VÉGH A., KRAUSE E. and PAPP J.G.: Cardiovascular effects of conventional sulfonylureas and glimepiride. Horm. Metab. Res., 28 (9): 496-507. Doi: 10.1055/s-2007-979841, 1996.

6- MÜLLER G., SATOH Y. and GEISEN K.: Extrapancreatic effects of sulfonylureas-a comparison between glimepiride and conventional sulfonylureas. Diabetes Res. Clin. Pract., 28: S115-S137. Doi:10.1016/0168-8227(95)01089-V, 1995.

7- VIJAYAKUMAR T.M., JAYRAM J., MEGHANA CHEEKIREDDY V., HIMAJA D., DHARMA TEJA Y. and NARAYANASAMY D.: Safety, Efficacy, and Bioavailability of Fixed-Dose Combinations in Type 2 Diabetes Mellitus: A Systematic Updated Review. Curr. Ther. Res., 84: 4-9. Doi: 10.1016/j.curtheres.2017.01.005, 2017.

8- NICE. Type 2 Diabetes: National Clinical Guideline for Management in Primary and Secondary Care (Update). Vol. 66. http://www.ncbi.nlm.nih.gov/books/NBK53885/, 2008.

9- KIM H. SOON, KIM D. MAN, CHA B. SOO, et al.: Efficacy of glimepiride/metformin fixed-dose combination vs metformin uptitration in type 2 diabetic patients inadequately controlled on low-dose metformin monotherapy:
A randomized, open label, parallel group, multicenter study in Korea. J. Diabetes Investig., 5 (6): 701-8. Doi: 10.1111/jdi.12201, 2014.

10- GONZÁLEZ-ORTIZ M., MARTÍNEZ-ABUNDIS E., GUERRERO ROMERO C.F., et al.: Eficacia y seguridad de la terapia hipoglucemiante oral combinada de glimepirida más metformina en una sola forma farmacéutica en pacientes con diabetes mellitus tipo 2 y falla secundaria a monoterapia con glibenclamida. Rev. Investig. Clin., 56 (3): 327-33, 2004.

11- GONZÁLEZ-ORTIZ M., GUERRERO-ROMERO J.F., VIOLANTE-ORTIZ R., et al.: Efficacy of glimepir ide/metformin combination versus glibenclamide/ metformin in patients with uncontrolled type 2 diabetes mellitus. J. Diabetes Complications, 23 (6): 376-9. Doi: 10.1016/j.jdiacomp.2008.09.002, 2009.

12- HOLSTEIN A., PLASCHKE A. and EGBERTS E.H.: Lower incidence of severe hypoglycaemia in patients with type 2 diabetes treated with glimepiride versus glibenclamide. Diabetes Metab. Res. Rev., 17 (6): 467473. Doi:10.1002/dmrr.235, 2001.

13- HARRIS S.B.: The power of two: An update on fixeddose combinations for type 2 diabetes. Expert. Rev. Clin. Pharmacol., 9 (11): 1453-62. Doi: 10.1080/17512433. 2016.1221758, 2016.

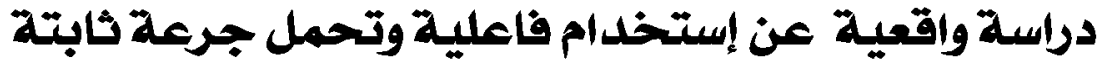

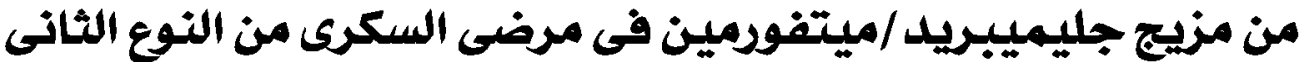

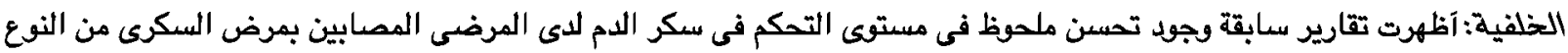

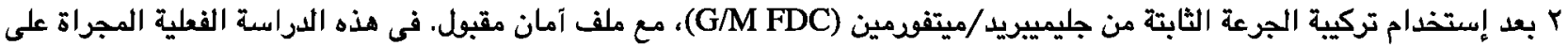
شريحة من المرضى المصريين، نهدف لبحث آمان وفعالية تركيية الجرعة الثابتة من جليمييريد/ميتفورمين (G/M FDC) بين المرضى المئين المصابين

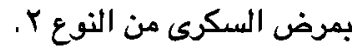

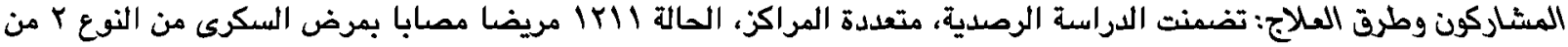

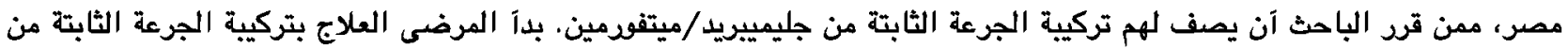

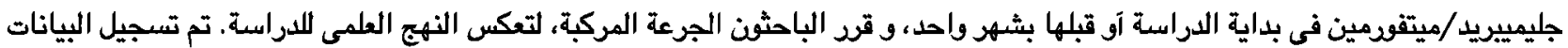

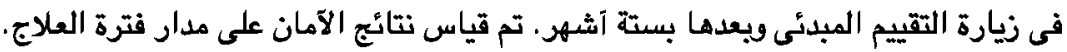

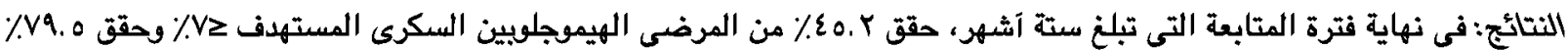

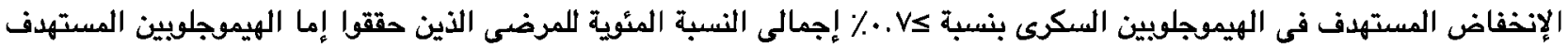

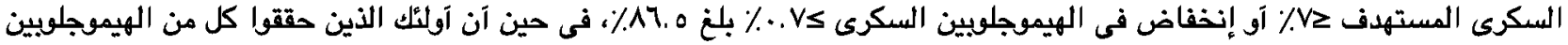

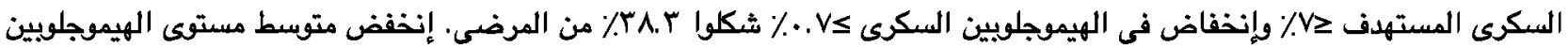

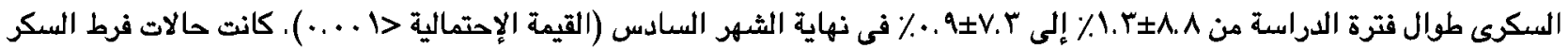

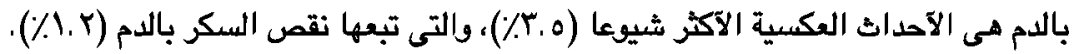

الخلاصة: تكون الوصفة الطبية لتركيية الجرعة الثابتة من جليميريد/ميتفومين في المرضى ممن يتلقون العلاج والمصابين بمرض السكرى الميى

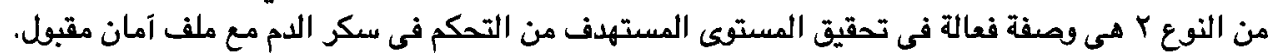

